\title{
A view of the epidemiologic landscape: how population-based studies can lend novel insights regarding the pathophysiology of glioblastoma
}

\author{
Ramya Tadipatri ${ }^{1}$, Kristopher Lyon ${ }^{2}$, Amir Azadi $^{1}$, Ekokobe Fonkem ${ }^{1}$ \\ ${ }^{1}$ Department of Neurology, Barrow Neurological Institute, Phoenix, AZ, USA; ${ }^{2}$ Department of Neurosurgery, Baylor Scott \& White Health, \\ Temple, TX, USA \\ Contributions: (I) Conception and design: E Fonkem; (II) Administrative support: E Fonkem; (III) Provision of study materials or patients: None; \\ (IV) Collection and assembly of data: All authors; (V) Data analysis and interpretation: All authors; (VI) Manuscript writing: All authors; (VII) Final \\ approval of manuscript: All authors. \\ Correspondence to: Ekokobe Fonkem, DO. 240 W Thomas Rd., Ste 403, Phoenix, AZ 85013, USA. Email: Ekokobe.fonkem@dignityhealth.org.
}

\begin{abstract}
Glioblastoma is an aggressive disease that is difficult to treat, in large part due to the high level of molecular heterogeneity that limits the utility of targeted therapies. As such, population studies have been essential in characterizing the factors that promote survival. In this review, we summarize the findings in these studies. Demographic trends, molecular markers (IDH mutation, MGMT promoter methylation, TERT promoter mutation, chromosome 1p19q codeletion, PTEN, and p53 among others), radiographic correlates (peritumoral edema, enhancement, cyst formation, necrosis, and invasion among others), nonsteroidal anti-inflammatory drug (NSAID) and statin use, and ketogenic diet have been assessed. Overall, studies have found that IDH mutation and MGMT promoter methylation are positive prognostic markers and TERT is a negative prognostic marker, although subgroup analysis has revealed differential responses. NSAID and statin use have also suggested improved survival reaching significance in some studies. Ketogenic diet has not yet been adequately assessed. Further studies to characterize the interplay of these and other genetic and environmental factors are warranted.
\end{abstract}

Keywords: Glioblastoma; population study; tumor markers

Submitted Dec 19, 2019. Accepted for publication Feb 05, 2020.

doi: $10.21037 /$ cco.2020.02.07

View this article at: http://dx.doi.org/10.21037/cco.2020.02.07

\section{Background}

Glioblastoma occurs with a global incidence of between 0.59 and 3.69 per 100,000 people. It accounts for more than $60 \%$ of all brain tumors in adults. Despite the rarity of the tumor, it accounts for $2.5 \%$ of all cancer-related deaths given its poor prognosis, with a median overall survival rate of 14-15 months after diagnosis with the Stupp regimen, 20.9 months after diagnosis with the addition of tumor treating fields as per the EF-14 trial, or 3 months after diagnosis when left untreated. Although it can occur at any age, the peak incidence is between 75 and 84 years of age with a median age of 64 at diagnosis. Whites have the highest incidence of glioblastoma compared with other ethnicities, and there is a higher incidence among nonHispanics compared with Hispanics (1-3).

Studies have found that survival rates decrease with increasing age, with one review of 139 glioblastoma patients showing a median overall survival of 12 months for patients under 65 years of age and 8 months for patients over 65 years of age $(\mathrm{P}=0.008)(4,5)$. Higher functional status was also correlated with improved survival, with a median overall survival of 10 months for patients who had Karnofsky performance status (KPS) greater than 70 and 6 months for patients who had KPS less than $70(\mathrm{P}=0.015)$, although Cox regression did not show that this was an independent factor. Patients who had a gross total resection had a median 
overall survival of 14 months, compared with 6 months for patients who had a subtotal resection $(\mathrm{P}<0.0001)(5)$. A meta-analysis of 28 studies supports this conclusion, with 16 studies demonstrating a statistically significant survival benefit with greater extent of resection (6). While initial studies did not show clear gender differences in survival, a recent review of 6,586 glioblastoma patients from the SEER database demonstrated a 5 -year survival rate of $6.8 \%$ among males and $8.3 \%$ among females $(\mathrm{P}<0.001)(7)$.

Glioblastoma tumor heterogeneity has posed a significant challenge in developing effective therapies. Numerous biomarkers have been identified, and the role and practical significance of these markers are difficult to establish when studied in isolation. Population-based studies provide realworld data which can be advantageous in guiding research direction.

With increasing availability of next generation sequencing, survival data can be obtained for patients with various biomarkers and combinations thereof. This can be analyzed in the context of demographic information, clinical characteristics, and radiographic characteristics (Figure 1), allowing for more personalized prognostication. Differential response to therapies may also be assessed, which can guide treatment plans for different populations, as well as allow for development of novel treatment targets.

Population studies may also allow for reappropriation of existing therapies for other conditions in glioblastoma treatment. Retrospective analysis of patients who are taking statins or nonsteroidal anti-inflammatory drugs (NSAIDs) or who are on a ketogenic diet can highlight potential benefits of these treatments and the specific populations that benefit.

\section{IDH mutations}

In 2016, the World Health Organization (WHO) revised its criteria for glioblastoma classification, dividing it into primary and secondary subtypes, with primary glioblastoma comprising IDH-wild type tumors and accounting for $90 \%$ of all diagnosed and secondary glioblastoma comprising IDH-mutant tumors and accounting for the remaining $10 \%$. This classification system was supported by three separate meta-analyses suggesting improved survival for IDH-mutant tumors, reporting pooled hazard ratios of 0.322 for progression free survival and 0.358 for overall survival (8). This was further supported by a multivariate analysis of 585 glioblastoma patients, which revealed that IDH $1 / 2$ was an independent prognostic marker, with
IDH-wildtype having a greater than 4-fold worse outcome compared with IDH-mutant tumor (9).

When focused on long term survivors of glioblastoma, a review of eleven studies revealed presence of IDH mutation in up to $40 \%$ of cases, compared with a reported prevalence of less than $4 \%$ in short term survivors. However, this difference was only significant in some studies, and in a cohort study of 40 long-term survivors there was also found to be no significant difference in progression free survival between IDH-wild type and IDH-mutant tumors. Overall, this appears to suggest that while IDH may be a factor in long term survival, it is likely not the sole factor (8).

A meta-analysis by Dai et al. not only confirmed an association between IDH1 mutations and decreased mortality, but also identified variable mortality benefit between populations. While Europeans experienced a $65 \%$ decreased risk of mortality, Asians experienced a $32 \%$ decreased risk (10). However, according to a SEER-based study, Asians also had the longest median survival (638 days) compared to other racial groups (11). SEER analysis shows no significant difference in percentage of IDH1 mutant patients across racial demographic groups, with $6.42 \%(95 \%$ CI, 4.26-8.97\%) in non-Latino whites, 5.74\% (95\% CI, $1.43-12.74 \%$ ) in Latinos, $8.33 \%$ (95\% CI, 0.01-37.94\%) in blacks, and $4.41 \%$ (95\% CI, $0.33-13.30 \%$ ) in Asians. The one-year survival rate was 38.2\% (95\% CI, 37.5-38.9\%) in non-Latino whites, compared with $41.7 \%$ (95\% CI, $39.4-44.0 \%)$ in Latinos. The five-year survival rate was 8.5\% (95\% CI, 6.9-10.2\%) in Latinos, compared with $4.4 \%$ (95\% CI, 4.0-4.8\%) in non-Latino whites and 44.3\% (95\% CI, 40.9-47.9\%) in Asians. Overall, Latino patients had improved survival outcomes compared with non-Latino whites and worse outcomes compared with Asians, despite similar percentages of IDH1 mutant patients (12).

\section{MGMT promoter methylation}

A review of thirteen studies showed that MGMT promoter methylation was detected in greater than $90 \%$ of long-term survivors, which was significantly higher than short-term survivors in most comparative studies. It was shown to be prognostic for improved survival across all subgroups (8).

With regard to treatment, MGMT promoter methylation has been shown to be a predictive factor for response to temozolomide, consistent with its silencing of a DNA repair protein allowing for susceptibility to alkylating agents. In a retrospective analysis of 206 patients, MGMT promoter methylation produced a significant overall survival 

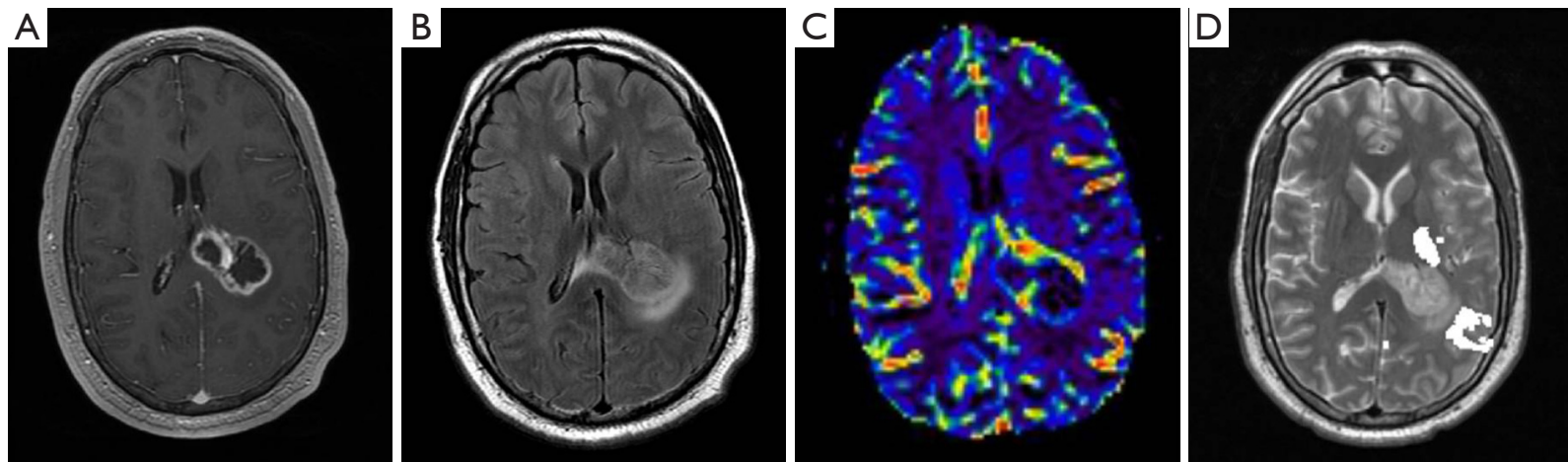

Figure 1 Glioblastoma appearance on magnetic resonance imaging (MRI). A 45-year-old male with newly diagnosed glioblastoma. (A) T1 post-contrast image; (B) T2-FLAIR image; (C) DSC image depicting decreased rCBV in central T1 hypointense region of necrosis and increased rCBV in periphery of tumor; (D) DTI image depicting white matter tracts. DSC, dynamic susceptibility contrast; rCBV, relative cerebral blood volume.

benefit but also showed a significant improvement with addition of temozolomide to radiotherapy, demonstrating an overall survival of 22.7 months with the combination of radiation and adjuvant temozolomide compared with 15.3 months with radiotherapy alone. Patients who were MGMT unmethylated did not demonstrate any survival benefit with addition of temozolomide to radiotherapy (13).

A study by Shu et al. analyzed mutation status and MRI-derived and clinical features including ADC signal, peritumoral edema, T1/FLAIR ratio, contrast enhancement, necrosis, cyst formation, and deep white matter invasion, age, KPS, and gender, and found no association with MGMT status (14).

There has also been an association described between MGMT promoter methylation and IDH mutation, as well as possible synergistic effects. In a study of 100 patients, MGMT methylated/IDH1-mutant patients survived significantly longer compared with all other subtypes, with an overall survival of 66.8 months, compared with 15.5 months for MGMT methylated/IDH1-wildtype and 11.1 months for MGMT unmethylated/IDH1-wildtype (15).

\section{TERT promoter mutations}

TERT promoter mutations are associated with enhanced telomere maintenance. Gliomas with only TERT promoter mutations are primarily grade IV gliomas, although according to one study, 39 of 406 (9.6\%) of TERT promoter mutations in glioma patients were grade II or grade III. These patients had a more aggressive course and were associated with poor survival, consistent with what is being termed a molecular glioblastoma (16). Gliomas that have mutations in both TERT promoter and IDH without $1 \mathrm{p} / 19 \mathrm{q}$ codeletion are relatively rare, accounting for $4 \%$ of all gliomas. Grade IV tumors with mutations in both TERT promoter and IDH are associated with poor survival despite the positive prognostic value of IDH mutations, while TERT promoter mutations in the presence of both IDH mutation and $1 \mathrm{p} / 19 \mathrm{q}$ codeletion are associated with improved survival (17).

TERT promoter mutations have been shown to be a negative prognostic indicator in some studies $(18,19)$. Shu et al. did not redemonstrate this correlation. However, there were several patterns of interest identified. Poor survival associated with TERT was only observed in patients exhibiting high peritumoral edema. There was also a correlation between TERT promoter mutation and central hypointense $\mathrm{T} 1$ core within an enhancing T1 postGAD hyperintense region on MRI, representing pathologic necrosis (14).

\section{Other molecular characteristics}

Although p53 mutation was found in higher frequency in long term survivors, this was not significant and there was no association with survival (8). Data on PTEN mutation was conflicting, with some studies showing increased prevalence and others showing decreased prevalence (8). Gain of chromosome 19 and 20 was more prevalent in long term survivors and associated with survival, and CD34 was upregulated in long term survivors (8). Other markers including EGFR amplification, CDKN2A/B homozygous 
deletion, H3F3A K27M, PI3KCA helical and kinase domain missense mutation, PDGFRA amplification, NF1 homozygous deletion, BRAF V600 mutation, and ATRX loss were not significantly elevated (8).

\section{Molecular subtypes}

EGFR is overexpressed in numerous human epithelial tumors as a result of gene amplification. This is frequently associated with EGFR gene mutations, most commonly EGFRv3 mutation. EGFRv3 mutations lead to a deletion of exons 2-7 of the EGFR gene resulting in inability to bind any ligand. EGFR mutations are present in $40 \%$ of glioblastoma tumors, with approximately half expressing the EGFRv3 variant. Data regarding prevalence in other tumor types is conflicting and limited by technical problems with detection. EGFR has therefore been identified as a potential therapeutic target for glioblastoma, with research on targeted therapy, CAR T cell therapy, and vaccines underway. However, although EGFR receptors seem to play a key role in inhibiting apoptosis and enhancing proliferation initially, they appear to play a limited role at advanced stages of tumorigenesis $(20,21)$.

Since introduction of the new WHO classification, The Cancer Genome Atlas has introduced a classification system by molecular subtype: proneural, classical, mesenchymal, and neural. The proneural subtype was characterized by IDH mutation, p53 mutation, PDGFRA amplification, CDK4/6 amplification, and MET amplification. The classical subtype was IDH and p53 wildtype but with PTEN loss and EGFR amplification with EGFRv3. The mesenchymal subtype was IDH-wildtype with NF1 mutation, p53 loss, and CDKN2A loss. The neural subtype was IDH-wildtype with no distinct characteristics. The classification system was obtained based on gene expression microarray analysis. These subtypes appear to have a relatively even distribution among long term survivors (22).

\section{Statins}

In addition to lipid lowering and cardiovascular effects, statins have been shown to modulate the inflammatory response, have anti-oxidant properties, inhibit the thrombogenic response, and decrease the oxidative stress response. In animal models, lovastatin was found to inhibit proliferation of lung, breast, prostate, and gastric cancer cells. Cytotoxic effects via apoptosis have also been demonstrated. Furthermore, lovastatin was found to inhibit attachment, mobility, and invasion in the cancer cell metastasis process (23). The precise mechanism remains unclear, although potential mechanisms including downregulation of NF-kappaB have been proposed. Cancer cell line sensitivity to statins was found to have a strong correlation with expression of TGF-beta target genes SERPINE1 and ZYX. Further experiments revealed that statin inhibition of HMG-CoA reductase results in TGF-beta inhibition through effects on Rho/ROCK phosphorylation of Smad3 (24).

A study of cancer patients in the entire Danish population who have received a diagnosis of cancer between 1995 and 2007, comprising approximately 300,000 patients, showed that patients who had previously undergone statin therapy had significantly reduced mortality, with hazard ratio of 0.85 for both all-cause mortality and cancer-related mortality (25). This has also been demonstrated in a study of 339 glioblastoma patients obtained from the Danish Cancer Registry, with statin users matched to non-users based on demographic data, which showed that prediagnostic statin use was associated with a reduced risk of death with hazard ratio of 0.79 for any statin use (borderline significance) and 0.66 for high-intensity statin use (statistically significant) (26). There has also been evidence of glioma prevention, with a case control study showing that simvastatin and lovastatin had inverse association with glioma with odds ratio 0.49 (27). However, preoperative statin use has not been found to improve overall or progression free survival after glioblastoma surgery in a population of 841 patients from MD Anderson (23).

\section{NSAIDs}

NSAIDs have also been extensively evaluated in risk of cancers. With respect to glioma, multivariate analyses have shown that high expression of COX-2 has been linked to poor survival of glioma patients. Inhibition of prostanoid synthesis by NSAIDs leads to a blockage of immunosuppressive lymphoid and myeloid cells within the glioma tumor microenvironment. This prompted particular interest in NSAID use as possible adjuvant therapy (28).

Many studies demonstrated reduced risk of colon cancer with NSAID use. Three case control studies have suggested an inverse relationship between NSAID use and glioma risk. Ferris et al reported an overall odds ratio of 0.68 , although only aspirin was found to have a significant effect (27). This appears to suggest that aspirin may influence glioma survival 
through a COX-independent process such as antiplatelet effect, particularly given the pro-metastatic and proinvasive effects of platelets through secretion of transforming growth factor beta, vascular endothelial growth factor, or platelet derived growth factor. A retrospective analysis aspirin use was again found to have better overall survival in patients with WHO grade III glioma, but no effect was seen with other NSAIDs. Aspirin use did not improve survival among patients with WHO grade IV gliomas, however (28).

\section{Ketogenic diet}

At a cellular level, there is evidence of increased glycolysis in glioblastoma, as there is often activation of the PI3 kinase/Akt signaling pathway as well as loss of p53 wildtype activity. Hypoxia in malignant glioma also stimulates accumulation of HIF-1 alpha and subsequent expression of genes involved in glucose metabolism. Increased glucose uptake has been observed in malignant gliomas through FDG-PET imaging (29). Given that glioma cells mainly consume glucose, dietary carbohydrate restriction has been proposed as a potential therapeutic strategy. In vitro and in vivo studies have demonstrated that the ketogenic diet, which is defined as a ratio of $4 \mathrm{~g}$ fat to $1 \mathrm{~g}$ protein and carbohydrate combined, inhibits cancer growth by inducing ketosis and increased lipolysis, mimicking the metabolic response to starvation when ketones become the main fuel source for the brain. While normal brain cells compensate for glucose restriction by metabolizing ketone bodies, glioblastoma cells do not have adequate capacity to do so (30). This appears to be due to decreased expression of critical ketolytic enzymes in tumor cells (31). Studies on beta-hydroxybutyrate, the main ketone produced during ketosis, have demonstrated that it is a specific class I histone deacetylase inhibitor which can activate specific genes to protect against oxidative stress (31). In mice, adjuvant ketogenic diet showed synergistic effect with radiation therapy as compared with radiation alone. The underlying mechanism of the synergistic effect remains unclear, although the ketogenic diet is presumed to increase cytotoxicity as a radiation modifier (32).

Population studies have revealed that elevated levels of insulin are associated with a worse prognosis in breast cancer patients, and increased IGF-1 is associated with increased risk of prostate cancer and breast cancer. Tumor rates were higher in diabetic patients treated with insulin releasing drugs such as sulfonylureas or with insulin, but not with insulin sensitizing drugs such as metformin, which suggests that insulin itself affects tumor formation and growth by acting as a growth factor. In patients with glioblastoma, higher blood glucose levels are associated with a worse prognosis (29).

A retrospective review of patients with high grade glioma treated with concurrent chemoradiotherapy and adjuvant chemotherapy showed that patients who were on a ketogenic diet had significantly lower serum glucose levels even in conjunction with steroids, although the study was not sufficiently powered to assess efficacy (33).

This data has been the basis for clinical trials investigating the impact of ketogenic diet. It was found to have no benefit as a single agent in recurrent glioma (29). As adjuvant therapy, it has been deemed safe and feasible, but its efficacy has yet to be established (30).

The modified Atkins diet is a less stringent version of a ketogenic diet which still generates serum ketones in patients. While a classic ketogenic diet is defined as a ratio of $4 \mathrm{~g}$ fat to $1 \mathrm{~g}$ protein and carbohydrate combined, the modified Atkins diet uses a ratio of $1-2 \mathrm{~g}$ fat to $1 \mathrm{~g}$ protein and carbohydrate combined. A feasibility study was conducted with 29 patients with grade II-IV astrocytoma following the modified Atkins diet during standard treatment. Ketosis was achieved in all 29 patients, and no serious adverse events occurred (34).

\section{Conclusions}

Over the past decade, there have been numerous population studies in glioblastoma, including both comparative and cohort studies, which have sought to uncover the determinants of survival in this elusive disease. This has included examination of demographics, molecular markers, radiographic features, concurrent or prior treatment with statins or NSAIDs, and diet. The studies analyzing these molecular markers and treatments are summarized in Table 1 and Table 2 respectively.

IDH mutation and MGMT promoter methylation have been identified by the majority of studies as indicators of improved survival. However, there have also been multiple studies that do not show a clear association. Similarly, TERT has been identified as a negative prognostic marker in some but not all studies. Subgroup analyses have revealed intriguing findings that suggest that these factors do not provide absolute benefit or risk, but rather improve or worsen outcomes in particular contexts. This reinforces the high level of heterogeneity observed in glioblastoma.

Most notably, MGMT promoter methylation has 
Table 1 Population studies in glioblastoma multiforme: molecular features

\begin{tabular}{|c|c|c|c|c|}
\hline Paper & $\begin{array}{l}\text { Number of } \\
\text { subjects }\end{array}$ & Type of study & Molecular features & Conclusions \\
\hline $\begin{array}{l}\text { Sonoda et al. } \\
\text { [2009] (35) }\end{array}$ & 40 & Comparative & MGMT, PTEN, TP53 & $\begin{array}{l}\text {-MGMT promoter methylation more prevalent in LTS and associated } \\
\text { with improved survival } \\
\text {-PTEN mutation and TP53 mutation low prevalence in LTS }\end{array}$ \\
\hline $\begin{array}{l}\text { Das et al. [2011] } \\
\text { (36) }\end{array}$ & 7 & Cohort & $\begin{array}{l}\text { MGMT, PTEN, EGFR, } \\
\text { chromosome 1p19q }\end{array}$ & $\begin{array}{l}\text {-MGMT promoter methylation and PTEN protein expression favorable } \\
\text {-Chromosome 1p19q deletion not significant }\end{array}$ \\
\hline $\begin{array}{l}\text { Barbus et al. } \\
\text { [2011] (37) }\end{array}$ & 23 & Comparative & IDH, FABP5, CRABP2 & $\begin{array}{l}\text {-IDH mutation more prevalent in LTS } \\
\text {-FABP5 higher in STS } \\
\text {-CRABP2 not significant suggesting different retinoic acid signaling } \\
\text { pathways }\end{array}$ \\
\hline $\begin{array}{l}\text { Labussiere et al. } \\
\text { [2014] (18) }\end{array}$ & 395 & Comparative & MGMT, TERT & $\begin{array}{l}\text {-TERT promoter mutation negative prognostic indicator } \\
\text {-TERT promoter mutation associated with IDH-wildtype, EGFR } \\
\text { amplification, CDKN2A deletion, and chromosome 10q loss but not } \\
\text { MGMT promoter methylation } \\
\text {-TERT promoter mutation has poorer outcome in EGFR wildtype group } \\
\text { but improved in EGFR amplification group }\end{array}$ \\
\hline $\begin{array}{l}\text { Hartmann et al. } \\
\text { [2013] (39) }\end{array}$ & 326 & Comparative & $\begin{array}{l}\text { IDH, MGMT, } \\
\text { chromosome 1p19q, } \\
\text { EGFR, TP53 }\end{array}$ & $\begin{array}{l}\text {-IDH not associated with LTS } \\
\text {-MGMT promoter methylation associated with survival } \\
\text {-More LTS were IDH mutant/MGMT promoter methylated } \\
\text {-Chromosome 1p19q deletion, EGFR, TP53 mutation not associated } \\
\text { with survival }\end{array}$ \\
\hline $\begin{array}{l}\text { Gerber et al. } \\
\text { [2014] (42) }\end{array}$ & 7 & Cohort & IDH, MGMT & $\begin{array}{l}\text {-IDH mutation rare } \\
\text {-MGMT promoter methylation strongly prognostic }\end{array}$ \\
\hline $\begin{array}{l}\text { Mazaris et al. } \\
\text { [2014] (43) }\end{array}$ & 476 & Comparative & MGMT, TP53, PTEN & $\begin{array}{l}\text {-MGMT promoter methylation not significant } \\
\text {-TP53 and PTEN more prevalent in LTS }\end{array}$ \\
\hline $\begin{array}{l}\text { Geisenberger } \\
\text { et al. [2015] (44) }\end{array}$ & 16 & Comparative & $\begin{array}{l}\text { MGMT, co-gain of } \\
\text { chromosome } 19 / 20\end{array}$ & $\begin{array}{l}\text {-MGMT not significant } \\
\text {-Co-gain of chromosome 19/20 more prevalent in LTS and associated } \\
\text { with survival }\end{array}$ \\
\hline $\begin{array}{l}\text { Amelot et al. } \\
\text { [2015] (45) }\end{array}$ & 207 & Comparative & IDH, MGMT & -IDH mutation not significant, MGMT unknown significance \\
\hline $\begin{array}{l}\text { Sarmiento et al. } \\
\text { [2016] (46) }\end{array}$ & 40 & Cohort & $\mathrm{IDH}$ & $\begin{array}{l}\text {-No significant difference in PFS between IDH-wildtype and } \\
\text { IDH-mutant }\end{array}$ \\
\hline
\end{tabular}

Table 1 (continued) 
Table 1 (continued)

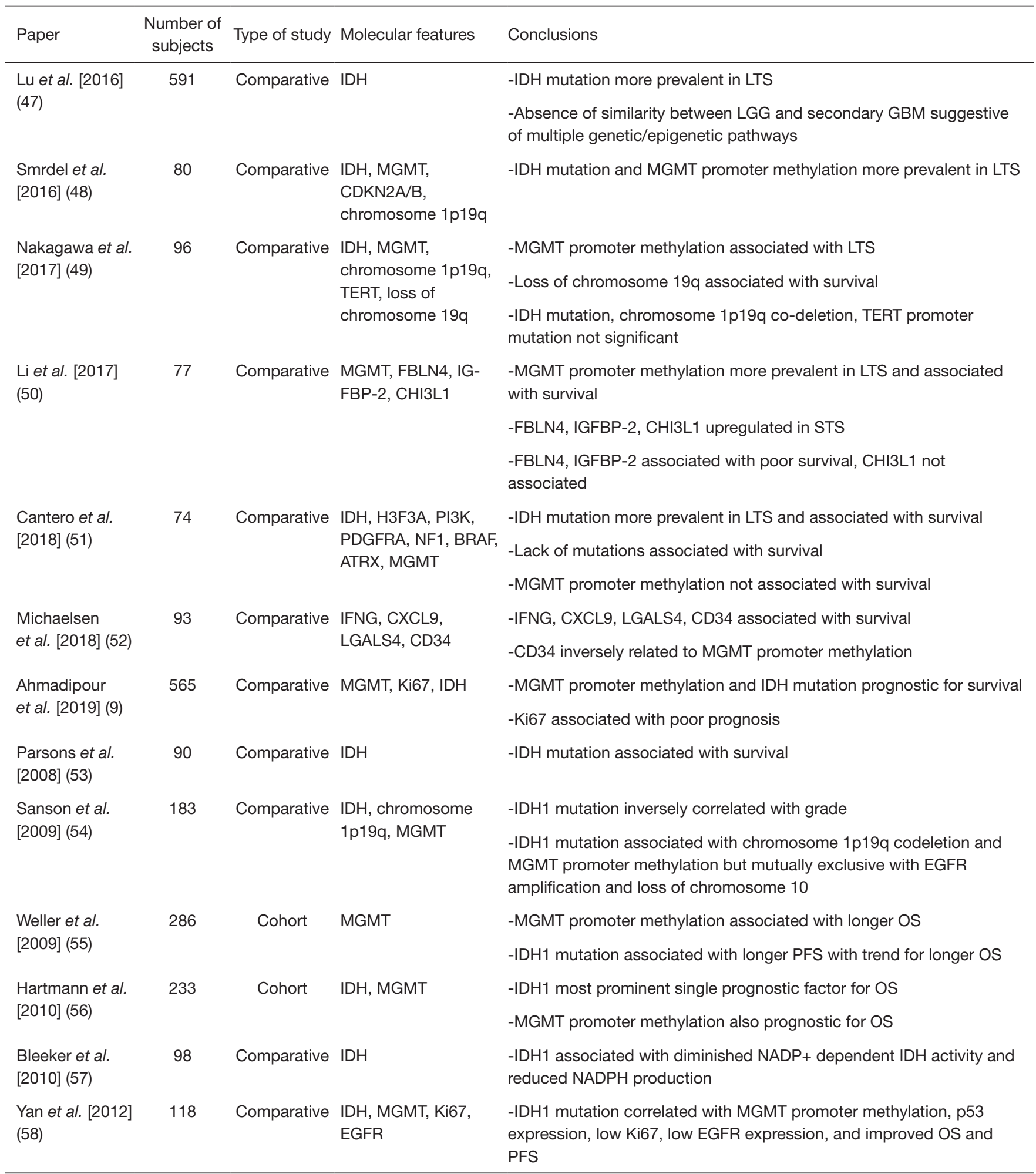

Table 1 (continued) 
Table 1 (continued)

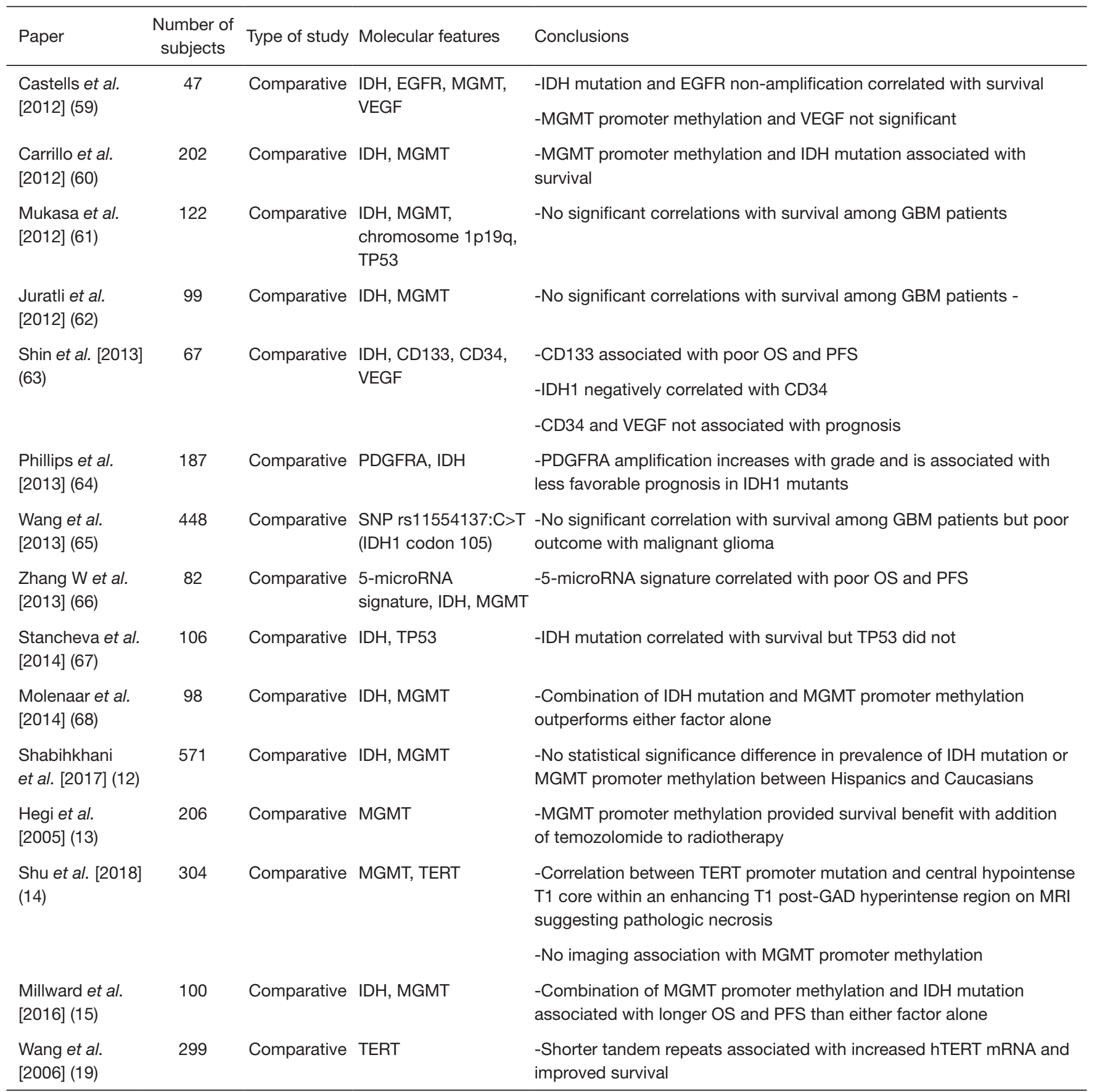

GBM, glioblastoma multiforme; LGG, low grade glioma; LTS, long term survivors; STS, short term survivors; OS, overall survival; PFS, progression free survival. 
Table 2 Population studies in glioblastoma multiforme: treatments

\begin{tabular}{|c|c|c|c|c|}
\hline Paper & $\begin{array}{l}\text { Number of } \\
\text { subjects }\end{array}$ & Type of study & Treatments & Conclusions \\
\hline $\begin{array}{l}\text { Bhavsar et al. } \\
\text { [2016] (23) }\end{array}$ & 284 & Cohort & $\begin{array}{l}\text { Preoperative } \\
\text { statin }\end{array}$ & -Preoperative statin use not correlated with survival \\
\hline $\begin{array}{l}\text { Gaist et al. } \\
\text { [2014] (26) }\end{array}$ & 339 & Cohort & $\begin{array}{l}\text { Prediagnostic } \\
\text { statin }\end{array}$ & $\begin{array}{l}\text {-Prediagnostic statin use was associated with reduced HR of death } \\
\text {-Increased duration or intensity of statin associated with reduced HR of } \\
\text { death }\end{array}$ \\
\hline $\begin{array}{l}\text { Ferris et al. } \\
\text { [2012] (27) }\end{array}$ & $\begin{array}{l}517 \text { cases, } \\
400 \text { controls }\end{array}$ & Case-control & $\begin{array}{l}\text { Prediagnostic } \\
\text { statin/NSAID }\end{array}$ & $\begin{array}{l}\text {-Simvastatin and lovastatin inversely associated with glioma } \\
\text {-Aspirin use inversely associated with glioma } \\
\text {-Duration of statin/NSAID use inversely related to glioma risk }\end{array}$ \\
\hline $\begin{array}{l}\text { Seliger et al. } \\
\text { [2018] (28) }\end{array}$ & $\begin{array}{l}1093 \text { grade } \\
\text { III/IV (862 GBM) }\end{array}$ & Comparative & $\begin{array}{l}\text { Concurrent or } \\
\text { prior statin/NSAID }\end{array}$ & $\begin{array}{l}\text {-Improved survival with aspirin in grade III glioma } \\
\text {-No survival benefit with NSAID or statin use }\end{array}$ \\
\hline
\end{tabular}

GBM, glioblastoma multiforme; HR, hazard ratio; NSAID, nonsteroidal anti-inflammatory drug.

been shown to provide survival benefit with addition of temozolomide to radiotherapy, in accordance with its mechanism of action. There is also some suggestion of synergistic effects between IDH mutation and MGMT promoter methylation given the profound increase in survival when both these factors are present.

Radiographic data has been used as another tool for characterizing the varied survival rates, particularly given the radiographic heterogeneity of glioblastoma in terms of features such as peritumoral edema, enhancement, necrosis, cyst formation, and invasion. Although no correlation with MGMT promoter methylation has been observed, TERT was found to be correlated with radiographic necrosis.

Demographic differences have also been described, including improved survival benefit for IDH1 mutations among Caucasians compared with Asians. Treatments primarily directed at managing cardiovascular risk factors, namely aspirin and statins, have shown some possible survival benefit as well. Ketogenic diet has been proposed as a potential treatment given the clinical correlation of low glucose level with survival and the theoretical benefit of limiting capacity for glycolysis, although sufficiently powered clinical trials have yet to be undertaken. Together, this suggests that diet and environmental factors may play a key role in altering the course of the disease.

While correlations have been discovered among various prognostic factors, these studies have also opened up many avenues for further study and elucidation of the nature of the interplay between these factors. As new patterns emerge, physicians may be able to provide more accurate prognostication and develop more individualized treatment plans.

\section{Acknowledgments}

Funding: None.

\section{Footnote}

Provenance and Peer Review: This article was commissioned by the Guest Editor (Rimas V Lukas) for the series "The Evolving Landscape of the Management of Glioblastoma" published in Chinese Clinical Oncology. The article has undergone external peer review.

Conflicts of Interest: All authors have completed the ICMJE uniform disclosure form (available at http://dx.doi. org/10.21037/cco.2020.02.07). The series "The Evolving Landscape of the Management of Glioblastoma" was commissioned by the editorial office without any funding or sponsorship. The authors have no other conflicts of interest to declare.

Ethical Statement: The authors are accountable for all 


\section{Page 10 of 12}

aspects of the work in ensuring that questions related to the accuracy or integrity of any part of the work are appropriately investigated and resolved.

Open Access Statement: This is an Open Access article distributed in accordance with the Creative Commons Attribution-NonCommercial-NoDerivs 4.0 International License (CC BY-NC-ND 4.0), which permits the noncommercial replication and distribution of the article with the strict proviso that no changes or edits are made and the original work is properly cited (including links to both the formal publication through the relevant DOI and the license). See: https://creativecommons.org/licenses/by-ncnd/4.0/.

\section{References}

1. Hanif F, Muzaffar K, Perveen K, et al. Glioblastoma Multiforme: A Review of its Epidemiology and Pathogenesis through Clinical Presentation and Treatment. Asian Pac J Cancer Prev 2017;18:3-9.

2. Tamimi AF, Juweid M. Epidemiology and Outcome of Glioblastoma. In: De Vleeschouwer S. editor. Glioblastoma. Brisbane (AU), 2017.

3. Stupp R, Taillibert S, Kanner A, et al. Effect of TumorTreating Fields Plus Maintenance Temozolomide vs Maintenance Temozolomide Alone on Survival in Patients With Glioblastoma: A Randomized Clinical Trial. JAMA 2017;318:2306-16.

4. Ghosh M, Shubham S, Mandal K, et al. Survival and prognostic factors for glioblastoma multiforme: Retrospective single-institutional study. Indian J Cancer 2017;54:362-7.

5. Dobran M, Nasi D, Chiriatti S, et al. Prognostic Factors in Glioblastoma: Is There a Role for Epilepsy? Neurol Med Chir (Tokyo) 2018;58:110-5.

6. Sanai N, Berger MS. Glioma extent of resection and its impact on patient outcome. Neurosurgery 2008;62:75364; discussion 264-6.

7. Tian $\mathrm{M}, \mathrm{Ma} \mathrm{W}$, Chen $\mathrm{Y}$, et al. Impact of gender on the survival of patients with glioblastoma. Biosci Rep 2018. doi: 10.1042/BSR20180752.

8. Gately L, McLachlan SA, Philip J, et al. Molecular profile of long-term survivors of glioblastoma: A scoping review of the literature. J Clin Neurosci 2019;68:1-8.

9. Ahmadipour Y, Jabbarli R, Gembruch O, et al. Impact of Multifocality and Molecular Markers on Survival of Glioblastoma. World Neurosurg 2019;122:e461-6.
Tadipatri et al. Population studies offer insights on glioblastoma

10. Dai Y, Ning X, Han G, et al. Assessment of the Association between Isocitrate Dehydrogenase 1 Mutation and Mortality Risk of Glioblastoma Patients. Mol Neurobiol 2016;53:1501-8.

11. Koshy M, Villano JL, Dolecek TA, et al. Improved survival time trends for glioblastoma using the SEER 17 populationbased registries. J Neurooncol 2012;107:207-12.

12. Shabihkhani M, Telesca D, Movassaghi M, et al. Incidence, survival, pathology, and genetics of adult Latino Americans with glioblastoma. J Neurooncol 2017;132:351-8.

13. Hegi ME, Diserens AC, Gorlia T, et al. MGMT gene silencing and benefit from temozolomide in glioblastoma. N Engl J Med 2005;352:997-1003.

14. Shu C, Wang Q, Yan X, et al. The TERT promoter mutation status and MGMT promoter methylation status, combined with dichotomized MRI-derived and clinical features, predict adult primary glioblastoma survival. Cancer Med 2018;7:3704-12.

15. Millward CP, Brodbelt AR, Haylock B, et al. The impact of MGMT methylation and IDH-1 mutation on long-term outcome for glioblastoma treated with chemoradiotherapy. Acta Neurochir (Wien) 2016;158:1943-53.

16. Brat DJ, Aldape K, Colman H, et al. cIMPACT-NOW update 3: recommended diagnostic criteria for "Diffuse astrocytic glioma, IDH-wildtype, with molecular features of glioblastoma, WHO grade IV". Acta Neuropathol 2018;136:805-10.

17. Eckel-Passow JE, Lachance DH, Molinaro AM, et al. Glioma Groups Based on 1p/19q, IDH, and TERT Promoter Mutations in Tumors. N Engl J Med 2015;372:2499-508.

18. Labussiere M, Boisselier B, Mokhtari K, et al. Combined analysis of TERT, EGFR, and IDH status defines distinct prognostic glioblastoma classes. Neurology 2014;83:1200-6.

19. Wang L, Wei Q, Wang LE, et al. Survival prediction in patients with glioblastoma multiforme by human telomerase genetic variation. J Clin Oncol 2006;24:1627-32.

20. Gan HK, Cvrljevic AN, Johns TG. The epidermal growth factor receptor variant III (EGFRvIII): where wild things are altered. FEBS J 2013;280:5350-70.

21. Felsberg J, Hentschel B, Kaulich K, et al. Epidermal Growth Factor Receptor Variant III (EGFRvIII) Positivity in EGFR-Amplified Glioblastomas: Prognostic Role and Comparison between Primary and Recurrent Tumors. Clin Cancer Res 2017;23:6846-55.

22. Verhaak RG, Hoadley KA, Purdom E, et al. Integrated genomic analysis identifies clinically relevant subtypes of 
glioblastoma characterized by abnormalities in PDGFRA, IDH1, EGFR, and NF1. Cancer Cell 2010;17:98-110.

23. Bhavsar S, Hagan K, Arunkumar R, et al. Preoperative statin use is not associated with improvement in survival after glioblastoma surgery. J Clin Neurosci 2016;31:176-80.

24. Xiao A, Brenneman B, Floyd D, et al. Statins affect human glioblastoma and other cancers through TGF-beta inhibition. Oncotarget 2019;10:1716-28.

25. Nielsen SF, Nordestgaard BG, Bojesen SE. Statin use and reduced cancer-related mortality. N Engl J Med 2012;367:1792-802.

26. Gaist D, Hallas J, Friis S, et al. Statin use and survival following glioblastoma multiforme. Cancer Epidemiol 2014;38:722-7.

27. Ferris JS, McCoy L, Neugut AI, et al. HMG CoA reductase inhibitors, NSAIDs and risk of glioma. Int J Cancer 2012;131:E1031-7.

28. Seliger C, Schaertl J, Gerken M, et al. Use of statins or NSAIDs and survival of patients with high-grade glioma. PLoS One 2018;13:e0207858.

29. Rieger J, Bahr O, Maurer GD, et al. ERGO: a pilot study of ketogenic diet in recurrent glioblastoma. Int J Oncol 2014;44:1843-52.

30. van der Louw E, Olieman JF, van den Bemt P, et al. Ketogenic diet treatment as adjuvant to standard treatment of glioblastoma multiforme: a feasibility and safety study. Ther Adv Med Oncol 2019;11:1758835919853958.

31. Schwartz KA, Noel M, Nikolai M, et al. Investigating the Ketogenic Diet As Treatment for Primary Aggressive Brain Cancer: Challenges and Lessons Learned. Front Nutr 2018;5:11.

32. Abdelwahab MG, Fenton KE, Preul MC, et al. The ketogenic diet is an effective adjuvant to radiation therapy for the treatment of malignant glioma. PLoS One 2012;7:e36197.

33. Champ CE, Palmer JD, Volek JS, et al. Targeting metabolism with a ketogenic diet during the treatment of glioblastoma multiforme. J Neurooncol 2014;117:125-31.

34. Woodhouse C, Ward T, Gaskill-Shipley M, et al. Feasibility of a modified Atkins diet in glioma patients during radiation and its effect on radiation sensitization. Curr Oncol 2019;26:e433-8.

35. Sonoda Y, Kumabe T, Watanabe M, et al. Long-term survivors of glioblastoma: clinical features and molecular analysis. Acta Neurochir (Wien) 2009;151:1349-58.

36. Das P, Puri T, Jha P, et al. A clinicopathological and molecular analysis of glioblastoma multiforme with longterm survival. J Clin Neurosci 2011;18:66-70.
37. Barbus S, Tews B, Karra D, et al. Differential retinoic acid signaling in tumors of long- and short-term glioblastoma survivors. J Natl Cancer Inst 2011;103:598-606.

38. Zhang K, Wang XQ, Zhou B, et al. The prognostic value of MGMT promoter methylation in Glioblastoma multiforme: a meta-analysis. Fam Cancer 2013;12:449-58.

39. Hartmann C, Hentschel B, Simon M, et al. Long-term survival in primary glioblastoma with versus without isocitrate dehydrogenase mutations. Clin Cancer Res 2013;19:5146-57.

40. Shinawi T, Hill VK, Krex D, et al. DNA methylation profiles of long- and short-term glioblastoma survivors. Epigenetics 2013;8:149-56.

41. Reifenberger G, Weber RG, Riehmer V, et al. Molecular characterization of long-term survivors of glioblastoma using genome- and transcriptome-wide profiling. Int J Cancer 2014;135:1822-31.

42. Gerber NK, Goenka A, Turcan S, et al. Transcriptional diversity of long-term glioblastoma survivors. Neuro Oncol 2014;16:1186-95.

43. Mazaris P, Hong X, Altshuler D, et al. Key determinants of short-term and long-term glioblastoma survival: a 14year retrospective study of patients from the Hermelin Brain Tumor Center at Henry Ford Hospital. Clin Neurol Neurosurg 2014;120:103-12.

44. Geisenberger C, Mock A, Warta R, et al. Molecular profiling of long-term survivors identifies a subgroup of glioblastoma characterized by chromosome 19/20 co-gain. Acta Neuropathol 2015;130:419-34.

45. Amelot A, De Cremoux P, Quillien V, et al. IDHMutation Is a Weak Predictor of Long-Term Survival in Glioblastoma Patients. PLoS One 2015;10:e0130596.

46. Sarmiento JM, Mukherjee D, Black KL, et al. Do LongTerm Survivor Primary Glioblastoma Patients Harbor IDH1 Mutations? J Neurol Surg A Cent Eur Neurosurg 2016;77:195-200.

47. Lu J, Cowperthwaite MC, Burnett MG, et al. Molecular Predictors of Long-Term Survival in Glioblastoma Multiforme Patients. PLoS One 2016;11:e0154313.

48. Smrdel U, Popovic M, Zwitter M, et al. Long-term survival in glioblastoma: methyl guanine methyl transferase (MGMT) promoter methylation as independent favourable prognostic factor. Radiol Oncol 2016;50:394-401.

49. Nakagawa Y, Sasaki H, Ohara K, et al. Clinical and Molecular Prognostic Factors for Long-Term Survival of Patients with Glioblastomas in Single-Institutional Consecutive Cohort. World Neurosurg 2017;106:165-73. 50. Li F, Li Y, Zhang K, et al. FBLN4 as candidate gene 
associated with long-term and short-term survival with primary glioblastoma. Onco Targets Ther 2017;10:387-95.

51. Cantero D, Rodriguez de Lope A, Moreno de la Presa R, et al. Molecular Study of Long-Term Survivors of Glioblastoma by Gene-Targeted Next-Generation Sequencing. J Neuropathol Exp Neurol 2018;77:710-6.

52. Michaelsen SR, Urup T, Olsen LR, et al. Molecular profiling of short-term and long-term surviving patients identifies CD34 mRNA level as prognostic for glioblastoma survival. J Neurooncol 2018;137:533-42.

53. Parsons DW, Jones S, Zhang X, et al. An integrated genomic analysis of human glioblastoma multiforme. Science 2008;321:1807-12.

54. Sanson M, Marie Y, Paris S, et al. Isocitrate dehydrogenase 1 codon 132 mutation is an important prognostic biomarker in gliomas. J Clin Oncol 2009;27:4150-4.

55. Weller M, Felsberg J, Hartmann C, et al. Molecular predictors of progression-free and overall survival in patients with newly diagnosed glioblastoma: a prospective translational study of the German Glioma Network. J Clin Oncol 2009;27:5743-50.

56. Hartmann C, Hentschel B, Wick W, et al. Patients with IDH1 wild type anaplastic astrocytomas exhibit worse prognosis than IDH1-mutated glioblastomas, and IDH1 mutation status accounts for the unfavorable prognostic effect of higher age: implications for classification of gliomas. Acta Neuropathol 2010;120:707-18.

57. Bleeker FE, Atai NA, Lamba S, et al. The prognostic IDH1( R132 ) mutation is associated with reduced NADP+-dependent IDH activity in glioblastoma. Acta Neuropathol 2010;119:487-94.

58. Yan $W$, Zhang $W$, You G, et al. Correlation of IDH1 mutation with clinicopathologic factors and prognosis in primary glioblastoma: a report of 118 patients from China. PLoS One 2012;7:e30339.

59. Castells X, Acebes JJ, Majos C, et al. Development of robust discriminant equations for assessing subtypes of

Cite this article as: Tadipatri R, Lyon K, Azadi A, Fonkem E. A view of the epidemiologic landscape: how population-based studies can lend novel insights regarding the pathophysiology of glioblastoma. Chin Clin Oncol 2021;10(4):35. doi: 10.21037/ cco.2020.02.07 glioblastoma biopsies. Br J Cancer 2012;106:1816-25.

60. Carrillo JA, Lai A, Nghiemphu PL, et al. Relationship between tumor enhancement, edema, IDH1 mutational status, MGMT promoter methylation, and survival in glioblastoma. AJNR Am J Neuroradiol 2012;33:1349-55.

61. Mukasa A, Takayanagi S, Saito K, et al. Significance of IDH mutations varies with tumor histology, grade, and genetics in Japanese glioma patients. Cancer Sci 2012;103:587-92.

62. Juratli TA, Kirsch M, Geiger K, et al. The prognostic value of IDH mutations and MGMT promoter status in secondary high-grade gliomas. J Neurooncol 2012;110:325-33.

63. Shin JH, Lee YS, Hong YK, et al. Correlation between the prognostic value and the expression of the stem cell marker CD133 and isocitrate dehydrogenase 1 in glioblastomas. J Neurooncol 2013;115:333-41.

64. Phillips JJ, Aranda D, Ellison DW, et al. PDGFRA amplification is common in pediatric and adult high-grade astrocytomas and identifies a poor prognostic group in IDH1 mutant glioblastoma. Brain Pathol 2013;23:565-73.

65. Wang XW, Boisselier B, Rossetto M, et al. Prognostic impact of the isocitrate dehydrogenase 1 single-nucleotide polymorphism rs11554137 in malignant gliomas. Cancer 2013;119:806-13.

66. Zhang W, Zhang J, Yan W, et al. Whole-genome microRNA expression profiling identifies a 5-microRNA signature as a prognostic biomarker in Chinese patients with primary glioblastoma multiforme. Cancer 2013;119:814-24.

67. Stancheva G, Goranova T, Laleva M, et al. IDH1/IDH2 but not TP53 mutations predict prognosis in Bulgarian glioblastoma patients. Biomed Res Int 2014;2014:654727.

68. Molenaar RJ, Verbaan D, Lamba S, et al. The combination of IDH1 mutations and MGMT methylation status predicts survival in glioblastoma better than either IDH1 or MGMT alone. Neuro Oncol 2014;16:1263-73. 